\title{
Bretonneau y Louis: Diferenciación y caracterización de la fiebre tifoidea
}

ENRIQUE LAVAL R.

\section{Bretonneau and Louis: Differentiation and characterization of typhoid fever}

Es casi imposible determinar desde cuándo existe la fiebre tifoidea, ya que las descripciones de enfermedades de las Edades Antigua y Media e incluso hasta muy avanzada la Moderna, eran demasiado imprecisas ${ }^{1,2}$.

Por lo tanto, su origen sería remoto, aunque se piensa que ya se encontraba en Atenas y Roma. Así Littré ha creído encontrarla en la especificación que hace Hipócrates de las diversas fiebres ("Causus") ${ }^{3}$.

Es muy probable como opinaba Trousseau, que se la involucrara en las reseñas del Synochus pestis (Cullen), Febris pútrida (Stoll), Fiebre maligna biliosa (Tirsot), Fiebre adinámica, ataxo-adinámica, etc ${ }^{1}$. En todo caso, ya no hay dudas de su existencia en los siglos XVI y XVII, englobada bajo el nombre de "fiebres pestilenciales"3.

Charles Achard (1860-1944), "precursor del descubrimiento de la insulina", opinaba que el conocimiento de una enfermedad, por regla general, seguía tres etapas: semiológica, anátomofisiológica y finalmente la etiológica. La fiebre tifoidea constituiría un buen ejemplo de esta aseveración ${ }^{1}$.

Con los descubrimientos bacteriológicos modernos, la concepción nosográfica ha variado un poco, por lo que es necesario volver a exponer algo de la historia de la enfermedad, manifestando que confundida con otras infecciones febriles, fue separada primero por Huxham en 1739, bajo el nombre de "fiebre lenta nerviosa", mientras que como "fiebre pútrida maligna o petequial”, designaba al tifus exantemático.

La confusión había persistido por mucho tiempo y los documentos dejados en el siglo XVI y parte del XVII, por Fracastorio, Baillou, Spigel, Willis y Sydenham, no proporcionaban más que elementos de interpretación todavía bastante vagos. Sin embargo, las nuevas observaciones de una autenticidad indiscutible, no tardaron en multiplicarse y gracias a Borsieri y Stoll, en 1785, las descripciones llegaron a ser cada vez más precisas. Es verdad que los trabajos de los "piretologistas", con sus innumerables divisiones, oscurecieron el problema durante cierto tiempo. Así, las clasificaciones, todas sintomáticas, adoptadas por Pinel (1798), en su "Nosografía de las fiebres esenciales", obligaron a buscar la exposición de la fiebre tifoidea en cuatro o cinco capítulos diferentes ${ }^{4-6}$.

Transcurrió mucho tiempo hasta que el desarrollo de la anatomía patológica y las observaciones epidemiológicas permitieron diferenciar la fiebre tifoidea, especialmente de las fiebres recurrentes y del tifus exantemático. Los primeros informes muy probables o seguros proceden del siglo XVII, siendo más abundantes los del siglo XVIII, pero después vuelve a ser más difícil la distinción entre las distintas epidemias que se extendieron por toda Europa, a consecuencia de las guerras $(1770 \text { a } 1815)^{2}$.

El período anátomo-patológico propiamente tal empezaría con los hallazgos de Prost (1802 ó 1804), que es, indudablemente, el primer autor que destacó la presencia de lesiones intestinales, en el curso de las fiebres que entonces se designaban como "mucosas, gástricas, adinámicas y atáxicas". Los trabajos de Petit y Serres (1812) fueron un progreso importante en el conocimiento de la enfermedad, que denominaron "fiebre entero-mesentérica”, evolucionando con evidentes lesiones intestinales y de los ganglios mesentéricos, descritas por ellos en la autopsia bajo tres formas: simple, botonosa y ulcerosa.

Ex Director del Hospital de Enfermedades Infecciosas Profesor Dr. Lucio Córdova, Santiago, Chile.

Recibido: 25 octubre 2004

Aceptado: 2 noviembre 2004 
Los aportes de Bretonneau (1818) y de Louis (1829), "marcan el momento crucial en la diferenciación de la fiebre tifoidea y su caracterización definitiva dentro del grupo de las pirexias en que estaba confundida" 1,7 .

"Cuando la pasión por una idea justa y el deseo de verificarla se adueñan de un hombre de curiosa inteligencia, despojado de todo conformismo, pueden transformarlo en héroe de una epopeya, a la que no le faltan detalles del genio ni el rigor del método, como tampoco la fuerza del raciocinio", entonces nos encontramos con Pierre Fidèle Bretonneau, uno de los más grandes y brillantes clínicos franceses. Sin duda, el más original”.

Nacido el 3 de abril de 1778 en Saint Georgessur-Cher, la Touraine, se dirige a los 17 años a París para seguir los cursos de la Escuela de Salud. Corvisart y Cuvier atraen su admiración. Al cabo de dos años y medio debe regresar a su provincia para mejorar su salud dañada. Es acogido por la castellana de Chenonceaux, Mme. Dupin, quien en largas conversaciones, hace comprender al joven Bretonneau, ávido de aprender, el eco de los filósofos y de los escritores de antaño, como Jean Jacques Rousseau. Algún tiempo después se casaría con Marie Thérese Adam. Vuelto a París, fracasa en su tercer examen de doctorado, contentándose con el título de Oficial de Sanidad y en 1801 vuelve a Chenonceaux para instalarse como practicante. Tanto el sobrino de Mme. Dupin como el prefecto de Tours, no lo dejan de reprender, presionándolo para continuar sus estudios, con el fin de que obtenga su título de médico. De nuevo en París, aprueba su tesis y en 1815 , es nombrado médico del Hospital de Tours. Ahí ejerce la docencia, siendo su actividad científica prodigiosa. Trousseau y Velpeau fueron sus discípulos predilectos. Se levantaba a las cuatro de la mañana, permaneciendo todo el día en el hospital, efectuando autopsias después del almuerzo, continuando con el examen de sus enfermos y acostándose a la medianoche. Con precisión, escrúpulos y paciencia, se dedica a la austera disciplina anátomo-clínica ${ }^{8-11}$.

Las epidemias de 1818-1819, le permiten reconocer la lesión característica de la fiebre tifoidea, descrita como ya lo señalamos, por Prost y después por Petit y Serres. Fija el sitio exacto de su ubicación en las placas de Peyer del yeyuno, ileon e intestino grueso, designando la enfermedad con el nombre de "dotinentería" (botón o forúnculo del intestino). En 1826, siguiendo el mismo y severo método anátomo-clínico, proclama igual unidad en el desorden de las "anginas malignas" y publica su famoso tratado de la "diphteritis". Como lo ha hecho con la fiebre tifoidea y la nueva faceta de la difteria, este autodidacta declara la especificidad de las enfermedades: etiológica, lesional, clínica, sobre las cuales establece el fundamento sólido del diagnóstico y las condiciones más racionales de la terapéutica ${ }^{12-16}$.

Según René Dubos, uno de los legados de Bretonneau sería: "A cada enfermedad su causa, para cada agente nocivo un efecto patológico bien definido". En 1855, Bretonneau escribía a Blache: "un germen especial propio a cada contagio, da nacimiento a cada enfermedad contagiosa: las plagas epidémicas no son engendradas ni diseminadas, más que por su germen reproductor" 17 .

Pierre Bretonneau falleció en 1862.

Si la personalidad de Louis no era tan brillante, como la de Laennec y de Bretonneau, no es menos cierto "el fervor atrayente y obstinado de este hombre, príncipe fecundo del método anátomo-clínico" ${ }^{2,18-21}$.

Había nacido Pierre Charles Alexandre Louis en Ay de la Champagne, el 14 de abril de 1787, en una familia de notarios y viñateros. Después de ocupar un puesto de escribiente de abogado, dejó toda relación con el Derecho, para efectuar sus estudios médicos en Reims, los que continuó y terminó en París. En 1814, partió para Rusia, estableciéndose en Odessa en 1816, donde ejerció durante cuatro años. En 1820, golpeado dolorosamente por su impotencia ante la considerable mortalidad de niños con angina y crup diftérico, vuelve a Francia "para ver si después de su partida se habían producido progresos en el tratamiento de esta enfermedad ${ }^{5,9}$. Encontró a su antiguo condiscípulo Chomel, sucesor de Laennec, quien le asignó dos salas en su Servicio de la Charité. Durante seis años recolectó las observaciones de los enfermos, creando los archivos clínicos para el servicio que lo había acogido, efectuando él mismo las autopsias, consagrando al menos dos horas a cada una ${ }^{8}$. Algunos de estos documentos fueron olvidados como las "Investigaciones anatómicas y patológicas sobre varias enfermedades agudas" (1826) y en otros que han permanecido, sobre "Investigaciones acerca de la enfermedad conocida con el nombre de gastroenteritis, fiebre pútrida, adinámica, etc" (1829), expresó con una exactitud perfecta, los síntomas y la anatomía patológica de la enfermedad, a la que impuso la denominación de fiebre tifoidea (del griego "humo, neblina"), adoptada poco tiempo después por Chomel y que llegó a ser clásica en Francia. En esta monografía Louis, completa a menudo y contra- 
dice algunas veces los trabajos sobre la "dotinentería” del gran Bretonneau. Destacó así mismo el papel específico de las placas y úlceras intestinales que representan el carácter anátomo-patológico especial de la enfermedad, igual como el tubérculo caracteriza el pulmón del tuberculoso.

Así su amplísima experiencia necrópsica le había permitido ya en 1825 , demostrar la frecuencia de la localización apical del tubérculo pulmonar. El comienzo de la tuberculosis en la región apical del pulmón y su propagación a las bases, sería la verdad más llamativa, de la que nadie se había percatado, transformándose en uno de los fundamentos de la clínica tisiológica $^{1,5,8,9}$.

Hay dos ideas fundamentales que sería necesario destacar en el pensamiento clínico de Louis: la necesidad de obtener observaciones clínicas íntegras, efectuando un interrogatorio y una exploración física completos, sin negar ninguna posibilidad clínica ni método de examen conocido. En segundo lugar, la obligación correlativa de tener archivos clínicos conservados minuciosamente, donde las observaciones sean clasificadas de tal manera, que se las puede encontrar fácilmente, para comparar y, si es posible, reducir a cifras sus enseñanzas. Por esto y mucho más, a Louis se le ha mencionado como creador del "método numérico", introduciendo la estadística en la Medicina ${ }^{6,8}$.

En 1872, a los 85 años falleció Louis, en los brazos de su mujer y de su alumno preferido Woillez, quien escribió su biografía.

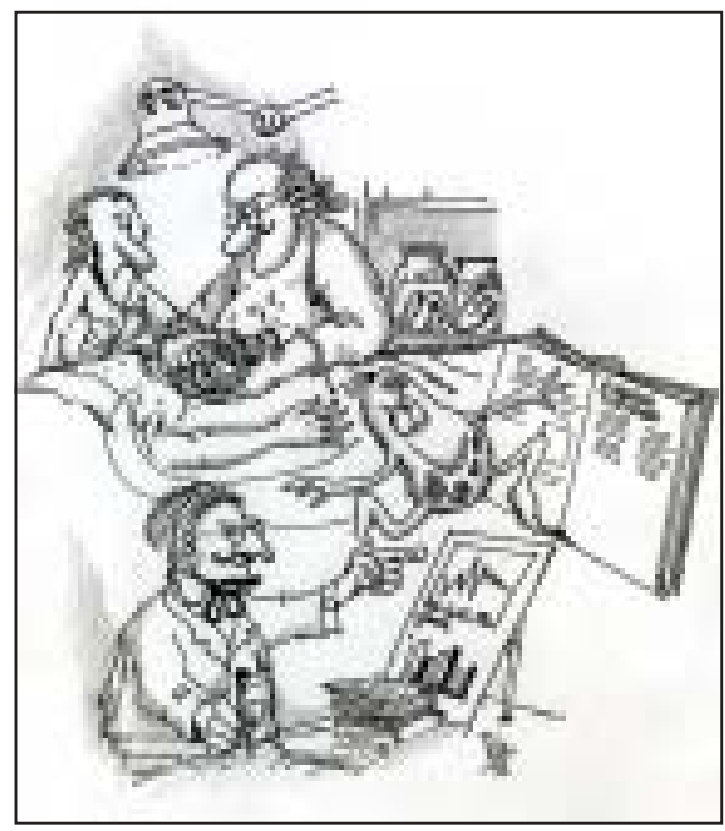

La unidad de la fiebre tifoidea habría sido definitivamente establecida y aceptada en esta última época, si la coexistencia de frecuentes epidemias de tifus exantemático en Alemania, Inglaterra y en los países escandinavos, no hubieran suscitado nuevas vacilaciones. Se necesitó algo menos de 20 años para determinar los límites respectivos de las dos enfermedades. A esta tarea se ha ligado a los médicos norteamericanos Shattuch (Boston), Gerhard y Pennock (Filadelfia), quienes habían estudiado la fiebre tifoidea en París; además Valleix, Rechoux, Barlow, Stewer y en fin W. Jenner, Forget, Godelier, Barralhier, etc.

La historia natural de la fiebre tifoidea estaba en adelante asentada en sus límites esenciales: la enfermedad se definía por su sintomatología y por sus lesiones anatómicas. La medicina contemporánea había de preocuparse más particularmente de la etiología y de la patogenia, del gran provecho de la terapéutica y de la profilaxis ${ }^{4,18,19}$.

Más o menos 60 años después de los trabajos de Bretonneau, en 1880, se inicia una nueva época con el descubrimiento del bacilo tífico por Eberth y, simultáneamente, por Koch y Wilh. En 1882, Gaffky deja demostrada en forma definitiva la significación etiológica de dicho microorganismo. En 1896, Achard y Bensaude, designaron como "bacilos paratíficos", a bacterias semejantes que aislaron de la orina y del pus articular, respectivamente, en dos pacientes de una enfermedad que evolucionó como fiebre tifoidea. Widal y Nobécourt en 1897 y Gewyn en 1898, identificaron también bacilos similares. En 1899 y 1903, aparecieron las publicaciones de Schottmüller, en las cuales señalaba que los bacilos paratíficos provocaban algunas veces enfermedades parecidas a la fiebre tifoidea y otras a una gastroenteritis aguda. Con posterioridad, Brion y Kaiser distinguieron dos tipos, siendo el último autor quien introdujo los nombres de fiebre paratifoidea A y $\mathrm{B}^{1,26}$.

Finalmente, debió transcurrir algo más de un siglo y cuarto (1948) para que T. E. Woodwart y J. E. Smadel dieran a conocer sus "comunicaciones preliminares sobre la acción eficaz del cloranfenicol en el tratamiento de la fiebre tifoidea"22.

Chile no fue una excepción en lo que se refiere a la confusión entre la fiebre tifoidea con otras enfermedades infecciosas, especialmente con el tifus exantemático. En efecto, no obstante su distinción anátomo-clínico en 1829, aquella persistió durante largo tiempo, por lo que la historia de la fiebre tifoidea en el país, podría considerarse moderna y casi contemporánea. 
Desde la Colonia hasta 1918, ambas enfermedades se habían confundido e identificado hasta límites inconcebibles y sólo a partir de la gran epidemia de tifus exantemático en aquel año, se comenzó a diferenciarlas con precisión y además el doctor Arturo Atria Osorio, jefe de la Sección Bacteriología del Instituto de Higiene, a "través de una prolija y minuciosa investigación histórica, demostró que el tifus exantemático había existido desde siempre en el país, como una entidad clínica propia y característica ${ }^{3,23}$.

Entre 1973 y 1983 hubo un aumento inusitado de casos de fiebre tifoidea en Chile, con tasas de morbilidad de hasta 120 por 100.000 habitantes $^{24}$. A partir de 1984 se produce una disminución sostenida de la incidencia, con una pequeña alza entre 1988 y 1991, para continuar descendiendo en forma mantenida hasta el presente, lo que ha significado una reducción de $94 \%$ en las tasas de morbilidad en 20 años (incidencia acumulada de 1,8 casos por 100.000 habitantes en 2002), según datos del Ministerio de Salud. Este importante descenso, probablemente estaría asociado a la mejoría sustancial obtenida en el saneamiento básico del país, en los últimos años ${ }^{25,26}$.

\section{Bibliografía}

1.- Pedro-Pons A, Farreras V P, Surós F J. Enfermedades infecciosas. Tomo VI p 212-3. Salvat Ed. Barcelona. España. 1952.

2.- Von Bergmann G, Staehelin R. Enfermedades Infecciosas. Tomo I. $1^{\text {a }}$ parte. p 857-8. Ed. Labor, Barcelona. España. 1942.

3.- Laval M E. Desarrollo histórico de la fiebre tifoidea en Chile (Apuntes inéditos).

4.- Debove G M, Achard Ch. Manuel de Médicine. Maladies Infectieuses. Tomo VIII, p 246-7. Rueff et Cie. Ed. París. Francia. 1897.

5.- BezanVon F, Labbé M, León B, Sicard J A. Pathologie Médicale. Maladies Infectieuses. Tomo I. $1^{\text {a }}$ parte, $p$. 156-9 Masson et Cie. Ed. París. Francia. 1927.

6.- Thoinot L, Ribierre P. Fievre Typhoïde. p. 5-9 J.B. Bailliere et Fils. Ed. París. Francia. 1912.
7.- Ledermann W. Una historia del bacilo de Eberth desde Junker hasta Germanier. Rev Chil Infectol 1999; 16: 232-6.

8.- Dumesmil R, Bonnet-Roy F. Les Médicins célèbres. p. 168-71; 228-9. Lucien Mazenod Ed. París Francia. 1947.

9.- Lain Entralgo P. Historia de la medicina moderna y contemporánea. p. 435. Ed. Científica Médica. Barcelona, España. 1954.

10.- Garrison F H. Historia de la Medicina. p 277-9. Ed. Interamericana. México. 1966.

11.- Diepgen P. Historia de la Medicina. p 232 y 392. Ed. Labor S.A. Madrid, España. 1932.

12.- Dumesmil R. Histoire Illustrée de la Médicine. p 1734. Librairie Plon. Ed. París, París. 1935.

13.- Laboratirio Bayer. Crónica de la Medicina $\mathrm{n}^{\circ} 5$. Bretonneau. p 268. 1998.

14.- Laveran A, Teissier J. Nuevos elementos de Patología y Clínica Médica. Fiebres tifoideas. Tomo I. p 36-69. Tipografía La Academia de Evaristo Ullastres. Barcelona, España. 1881.

15.- Brugsch Th. Tratado de Patología Médica. Tomo I. p 363-4. Ed. Labor S.A. Barcelona, España.

16.- Péquignot H. Précis de Pathologie Médicale. Tomo I. Géneralités. Maladies Infectieuses. p 196-7. Masson et Cie. Ed. parís, Francia, 1967.

17.- Bariety M, Coeuy Ch. Histoire de la Médicine. p 614/ 852. Librairie Arthème Fayard. París, Francia. 1963.

18.- Sergent E, Ribadeau, Dumas L, Babonneix L. Tratado de Patología Médica y de Terapéutica Aplicada. p 59. Infecciones por gérmenes conocidos. Ed. Pubul. Barcelona, España. 1934.

19.- Taylor Becovitz Z. Clinical tropical medicine. p 548. Ed. Paul B. Hoeber. N. York, USA. 1944.

20.- Castiglioni A. Historia de la medicina. p 606. Salvat Ed. Barcelona, España. 1941.

21.- Lyons A S, Petrucelli R J. Medicine. An illustrated history. p 513. Abradale Press. Rawls. W. Ed. N. York, USA, 1987.

22.- Parry Ch; Tran Tinh Hien; Dougan G.; White N; Farrar J. Typhoid fever. N Engl J Med 2002; 347: 1770-82.

23.- Laval R E. Chile 1918: las dos epidemias. Rev Chil Infect 1999; 16: 70-6.

24.- Laval R E, Vitali C J. Fiebre paratifoidea A y B. Estudio clínico de 666 casos. Rev Chil Infect 1984; 1: 8999.

25.- Enfermedades de Notificación Obligatoria. El Vigía 2002; 18: 34.

26.- Enfermedades de Notificación Obligatoria. El Vigía 2003; 19: 15. 